\title{
Gender Specific Association of RAS Gene Polymorphism with Essential Hypertension: A Case-Control Study
}

\author{
Kh. Dhanachandra Singh, ${ }^{1}$ Ajay Jajodia, ${ }^{2}$ Harpreet Kaur, \\ Ritushree Kukreti, ${ }^{2}$ and Muthusamy Karthikeyan ${ }^{1}$ \\ ${ }^{1}$ Department of Bioinformatics, Alagappa University, Karaikudi, Tamil Nadu 630 004, India \\ ${ }^{2}$ Genomics and Molecular Medicine Unit, CSIR-Institute of Genomics and Integrative Biology, Mall Road, New Delhi 110007, India
}

Correspondence should be addressed to Muthusamy Karthikeyan; mkbioinformatics@gmail.com

Received 23 February 2014; Accepted 24 March 2014; Published 17 April 2014

Academic Editor: James Stockand

Copyright (C) $2014 \mathrm{Kh}$. Dhanachandra Singh et al. This is an open access article distributed under the Creative Commons Attribution License, which permits unrestricted use, distribution, and reproduction in any medium, provided the original work is properly cited.

\begin{abstract}
Renin-angiotensin system (RAS) polymorphisms have been studied as candidate risk factors for hypertension with inconsistent results, possibly due to heterogeneity among various genetic and environmental factors. A case-control association study was conducted to investigate a possible involvement of polymorphisms of three RAS genes: AGT M235T (rs699), ACE I/D (rs4340) and G2350A (rs4343), and AGTR1 A1166C (rs5186) in essential hypertensive patients. A total of 211 cases and 211 controls were recruited for this study. Genotyping was performed using PCR-RFLP method. The genotype and allele distribution of the M235T variant differed significantly in hypertensives and normotensives $(\mathrm{OR}-\mathrm{CI}=2.62(1.24-5.76), P=0.006$; OR-CI $=0.699(0.518-0.943)$, $P=0.018$ ), respectively. When the samples were segregated based on sex, the 235TT genotype and T allele were predominant in the female patients (OR-CI $=5.68(1.60-25.10), P=0.002$; OR-CI $=0.522(0.330-0.826), P=0.005)$ as compare to the male patients $(\mathrm{OR}-\mathrm{CI}=1.54(1.24-5.76), P=0.34$; OR-CI $=0.874(0.330-0.826), P=0.506)$, respectively. For ACE DD variant, we found overrepresentation of "I"-allele (homozygous II and heterozygous ID) in unaffected males which suggest its protective role in studied population $(\mathrm{OR}-\mathrm{CI}=0.401(0.224-0.718) ; P=0.0009)$. The M235T variant of the AGT is significantly associated with female hypertensives and ACE DD variant could be a risk allele for essential hypertension in south India.
\end{abstract}

\section{Introduction}

Human essential hypertension (EHT) is a multifactorial trait with a complex genetic basis. This complex disease is due to the consequence of an interaction between various environmental and genetic factors and it plays a major role in blood pressure (BP) variation [1]. It does not follow the Mendelian mode of transmission [2]. The genetic contribution is estimated to be between $30 \%$ and $40 \%$ of BP variation [3]. In recent years, a series of genes have been proposed to influence the mechanism of blood pressure. Some evidences of association between these genes had been reported [46 ] but on the contrary these associations were not always significant [7].

More than 150 candidate genes have been implicated in the regulation of blood pressure that is linked to several pathways. Among these genes, RAS has significant direct involvement in the BP regulation as it is reported in several studies and most of the antihypertensive drugs are targeting this system. The genetic variation of RAS encoding genes, angiotensinogen $(A G T)$, angiotensin-1-converting enzyme $(A C E)$, and angiotensin II type 1 receptor (AGTR1), were associated with EHT and have been important genes for the association studies in various populations [8-10]. AGT, the natural substrate of RAS, is synthesized in the liver and released into blood circulation. The potential role of $A G T$ gene in hypertension was originally explored by Jeunemaitre group through linkage and association study in the causation of human EHT in Utah and French populations [4]. AGT variants have been shown to associate with serum AGT in black and white children, providing a potential mechanism for genetic associations $[11,12]$. Among the identified major molecular variants of $A G T, \mathrm{M} 235 \mathrm{~T}$ and $\mathrm{T} 174 \mathrm{M}$ variants had a significant association with hypertension [13]. But 
associations with these variants are found to be contradictory in different populations [14]. Two different meta-analyses in Chinese populations have also confirmed that $\mathrm{T}$ allele of AGT M235T polymorphism is associated with essential hypertension $[15,16]$.

$A C E$ is a key zinc metalloenzyme of the RAS and is widely distributed in the kidney [17]. The ACE catalyzes the conversion of angiotensin I to the biologically active peptide, angiotensin II, which is involved in the control of fluid electrolyte balance and systemic blood pressure [18]. This polymorphism is characterized by the presence (insertion) or absence (deletion) of a 287 bp AluYa5 element inside intron 16. Although I/D polymorphism is located in intronic region of the $A C E$ gene, several investigators have found that the $\mathrm{D}$ allele is related to increased activity of $A C E$ in serum. The highest serum $A C E$ activity was seen in the DD genotype while the lowest was seen in the II genotype [19]. Among the ACE gene polymorphisms of exon 17, G2350A variant has the most significant effect on plasma $A C E$ concentrations as it accounts for $19 \%$ of the total variance in $A C E$ plasma levels. $A C E \mathrm{I} / \mathrm{D}$ is in linkage disequilibrium (LD) with $A C E$ G2350A and both the variants are associated with essential hypertension with contradictory result $[20,21]$. Metaanalyses in different studies also found that DD genotype of ACE I/D polymorphism [22, 23] and AA genotype of ACE G2350A polymorphism are associated with essential hypertension [24].

The AGTR1, a receptor for angiotensin II, is a member of the G-protein-coupled receptor super family expressed in most tissues, where receptor activation leads to vasoconstriction, water retention, and vascular smooth muscle cell proliferation and hypertrophy $[25,26]$. The polymorphism A1166C in the $3^{\prime}$ untranslated region of the AGTR1 gene was detected in study by Bonnardeaux et al., (1994) who also identified its association with hypertension [27]. Several recent findings and meta-analysis reported that it is associated with essential hypertension [28, 29]; however, conflicting results are also reported by few studies [30, 31].

The goal of the present analysis is to assess the effect of a combination of variants at different loci of pathophysiological pathway of RAS genes in south Indian population. In this case-control study, we examined possible associations between polymorphisms of the AGT, ACE, and AGTR1 genes and hypertension in the south Indian population age between 30 and 70 years. We therefore determined the association between AGT M235T, ACE I/D, ACE G2350A, and AGTR1 A1166C polymorphisms in the study population.

\section{Materials and Methods}

2.1. Study Population. Blood sample $(5 \mathrm{~mL})$ were collected from patients $(n=211)$ and control subjects $(n=211)$ between the age of 30 and 70 years from the clinics after informed consent form was obtained from all the participating volunteers. Patients were diagnosed in accordance with JNC 7 guidelines [32] and hypertension was defined as systolic BP (SBP) of $\geq 140 \mathrm{~mm} \mathrm{Hg}$ and/or diastolic BP (DBP) of $\geq 90 \mathrm{~mm} \mathrm{Hg}$ or prior diagnosis of essential hypertension by a physician or current use of antihypertensive medication or individual having a history of hypertension. All the cases included in the study were of essential hypertension as diagnosed by the physician. Cases with secondary forms of hypertension, myocardial infarction, and cerebrovascular incidents or other systemic diseases and any major illness in last six month before the sample collection were excluded. Normotensive individuals $(n=211)$ with SBP $\leq 120 \mathrm{~mm} \mathrm{Hg}$ and $\mathrm{DBP} \leq 80 \mathrm{~mm} \mathrm{Hg}$ with matched age, sex, and location were selected as controls. Control individuals were also devoid of associated conditions like vascular diseases, diabetes, and other systemic diseases or under any medication and BMI of $\leq 25 \mathrm{~kg} / \mathrm{m}^{2}$. This study was approved by Institutional Ethical Committee. Clinical data and family history were recorded in the questionnaire for all the participants. All the participants belonged to Dravidian ancestry living in Tamil Nadu, south India. All the patients' samples were collected from the Outpatients Department of Government Hospitals of Tamil Nadu, south India. Control samples were also collected from the volunteers living in same place and origin. Genomic DNA was extracted using modified Miller's protocol [33] and it was quantified spectrophotometrically by $\mathrm{OD}_{260} / \mathrm{OD}_{280}$ ratio. Genotyping was performed with PCRRFLP and allele specific primer methods. Primer, restriction enzyme and PCR conditions are shown in Supplementary Table 1 in Supplementary Material available online at http://dx.doi.org/10.1155/2014/538053.

2.2. Statistical Analysis. Differences in the ACE, AGTR1, and $A G T$ genotype frequencies between the cases and controls were compared using chi-square statistics. The odds ratio (OR) and 95\% confidence interval (CI) were used as a measure of the strength of the association between genotype frequencies. Statistical significance accepted level was $P<$ 0.05 . The frequencies of the marker alleles were estimated by allele counting method and tested for Hardy-Weinberg equilibrium (HWE). All the statistical calculations were carried out using PLINK 1.07 [34] and STATA 11.0. Power of the study was calculated using PS-Power and sample size calculation [35].

MDR (multidimensionality reduction) analysis was performed using MDR software [36] to determine the genotypic combination that may confer high or low risk for EHT and also to determine the single most predictive genetic (genegene/gene-environment) model for EHT. Briefly, the MDR was comprised of two steps. First, the best combination of multifactors was chosen. Second, the combinations of genotypes are classified into high- and low-risk groups [37]. Interaction analysis was performed in the open source MDR software package (v.2.0) available at http://www.epistasis.org/ [38].

\section{Results}

Association studies of genetic polymorphisms and trait for detecting the complex diseases remain controversial. However, the association study of allele and genotype frequencies of candidate genes with the unaffected and affected subjects to understand the genetic etiology of complex human traits remains an efficient method [39-41]. Taking this method 
TABLE 1: Sample size, sex ratio, and basic characteristics (means, standard deviation) of study sample.

\begin{tabular}{lcc}
\hline & Cases $(n)$ & Controls $(n)$ \\
\hline$N$ & 211 & 211 \\
Male & 109 & 130 \\
Female & 102 & 81 \\
Age (years), male & $54.56 \pm 13.04$ & $43.71 \pm 14.17$ \\
Age (years), female & $54.37 \pm 12.25$ & $43.90 \pm 13.57$ \\
\hline
\end{tabular}

$N$ : sample size.

into consideration, we determined the possible association of genetic polymorphisms of RAS genes with EHT with the south Indian subjects. To the best of our knowledge, few studies have been published in RAS gene polymorphisms with the genotype and allele based association study in Indian subjects. But, large number of studies has reported association between EHT and ACE [42-45] or AGT [46-48] gene polymorphism but lack of haplotype based association of the RAS gene with the EHT in south Indian population. Probably this could be the first comprehensive reports on RAS gene polymorphisms with association study of genotype and haplotype in relation to EHT in south Indian subjects.

A total of 422 subjects were recruited for this study, out of which 211 subjects were cases and 211 subjects were controls. Among the patients, 109 (51.66\%) are males and 102 (48.34\%) are females, whereas in control subjects $130(61.61 \%)$ are males and $81(38.99 \%)$ are females (Table 1$)$. The mean age of control subjects is $43.71 \pm 14.17$ years for males and $43.90 \pm 13.57$ years for females. The mean ages of male patients are $54.56 \pm 13.04$ years and $54.37 \pm 12.25$ years for females. The difference in the distribution of epidemiological features were found to be significant between cases and controls with respect to gender $\left(\chi^{2}=4.26 ; P=0.039\right)$.

Genotype distributions of all four studied polymorphisms were compatible with HWE expectation in cases as well as in controls. Differences between cases and controls in allele/genotype frequency distributions that were observed for AGT M235T and ACE I/D polymorphism (Tables 2 and 3) with $T$ and $D$ allele are more prevalent in cases than in controls except for ACE I/D polymorphism in females. Genotype/allele distribution of ACE G2350A and AGTR1 A1166C polymorphisms was similar in both cases and controls (Tables 2 and 3 ).

To test the association of RAS gene polymorphisms with hypertension, genotype odds ratio was calculated for all the variants reported in the table.

3.1. AGT M235T Polymorphism. The genotype distribution of M235T polymorphism was significantly different between case and control subjects. Taking the MM genotype of the AGT M235T polymorphism as a reference, association of the MT genotype was 2.40 (95\% CI: 1.11-5.37) and TT genotype was 2.62 (95\% CI: 1.24-5.76), indicating a dominant effect of the $\mathrm{T}$ on risk and $\mathrm{T}$ allele is highly associated with hypertension in our recessive model (Table 4). Allelic association does not withstand after multiple corrections (alpha value $0.05 / 4=$ 0.013; Table 2). Furthermore, the samples were segregated for

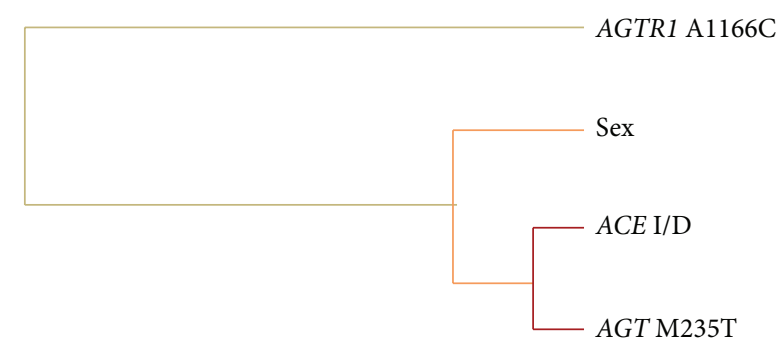

Weak interaction Strong interaction

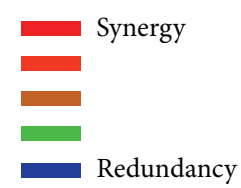

FIGURE 1: Interaction dendrogram for the four polymorphisms of RAS gene modeled by the MDR method. A red or orange line indicates synergistic or nonadditive relationship yellow line, independency, or additivity.

subgroup analysis on the basis of gender and $\mathrm{T}$ allele was associated with the female patients (OR: 0.522; 95\% CI: 0.3300.826) after applying the Bonferroni corrections (Tables 2 and 3).

3.2. ACE I/D Polymorphism. Considering I/D polymorphism, the distribution of genotypes did not differ significantly between EHT patients and controls through a slight increase in the frequency of DD (39.34\%) homozygous that was observed among patients as compared to controls (31.75\%) (Table 3). However, our results revealed overrepresentation of "I"-allele carriers (homozygous II and heterozygous ID) in male control subjects (Table 4) which suggests its protective role in studied population. This association was estimated as odds ratio of 0.401 with $95 \%$ CI $0.224-0.718$ and withstand after multiple correction (Table 4).

3.3. ACE G2350A Polymorphism. The genotype distribution of ACE G2350A polymorphism did not differ significantly between EHT patients and control subjects, and the allele frequencies were in HWE in both groups (Tables 3 and 4).

3.4. AGTR1 A1166C Polymorphism. Genotyping frequencies of A1166C polymorphisms were identified for all the EHT patients and control subjects. Our result shows that there is no significant difference in genotype and allelic frequencies in EHT patients and controls. Furthermore, the allele frequencies are consistent with the HWE in both cases and controls (Tables 2 and 3).

3.5. Analysis of Epistatic Interaction. To elaborate the findings of the analysis, MDR analysis was applied to detect and characterize high-order gene-gene and gene-environmental interactions in cases and controls. Figure 1 illustrates the 
TABLE 2: Distributions of allele frequencies in cases and controls stratified gender wise.

\begin{tabular}{lccccccc}
\hline Gene & Allele & Minor allele & Freq. minor allele case & Freq. minor allele control & $\chi^{2}$ & OR & $P$ value \\
\hline AGT M235T & M/T & M & 0.254 & 0.327 & 5.527 & $0.699(0.518-0.943)$ & $\mathbf{0 . 0 1 8}$ \\
Female & & & 0.226 & 0.358 & 7.797 & $0.522(0.330-0.826)$ & $\mathbf{0 . 0 0 5}$ \\
Male & & & 0.280 & 0.308 & 0.443 & $0.874(0.588-1.299)$ & 0.506 \\
ACE I/D & I/D & I & 0.398 & 0.462 & 3.524 & $0.770(0.586-1.012)$ & 0.060 \\
Female & & & 0.441 & 0.420 & 0.169 & $1.091(0.719-1.656)$ & 0.681 \\
Male & & & 0.357 & 0.489 & 8.265 & $0.584(0.404-0.844)$ & $\mathbf{0 . 0 0 4}$ \\
ACE G2350A & G/A & $\mathrm{A}$ & 0.173 & 0.164 & 0.136 & $1.070(0.746-1.535)$ & 0.713 \\
Female & & & 0.172 & 0.210 & 0.866 & $0.780(0.461-1.318)$ & 0.352 \\
Male & & & 0.174 & 0.135 & 1.444 & $1.357(0.824-2.236)$ & 0.229 \\
AGTR1 Al166C & A/C & $\mathrm{C}$ & 0.384 & 0.401 & 0.244 & $0.933(0.708-1.230)$ & 0.622 \\
Female & & & 0.363 & 0.414 & 0.985 & $0.807(0.529-1.233)$ & 0.321 \\
Male & & & 0.404 & 0.392 & 0.064 & $1.049(0.726-1.515)$ & 0.800 \\
\hline
\end{tabular}

$\chi^{2}$ : Chi-square with 1 degree of freedom; OR: odds ratio; ${ }^{*} P<0.05$ : statically significant (alpha value $0.05 / 4$ ).

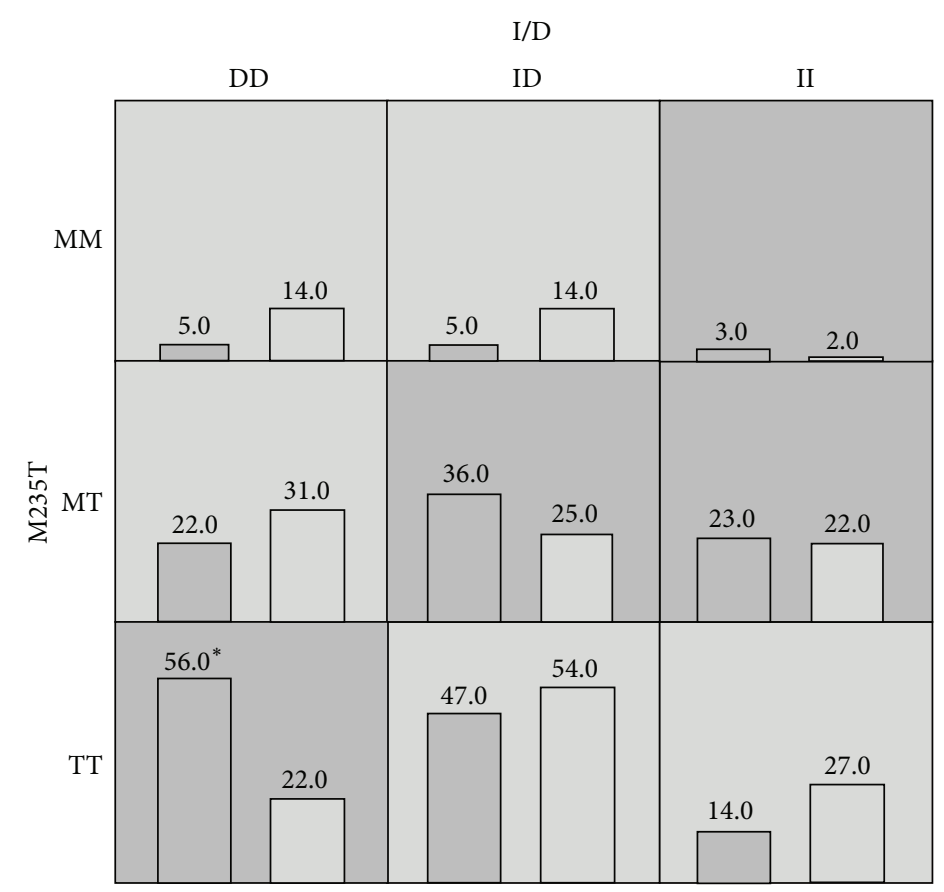

FIGURE 2: Distribution of high-risk (dark shaded) and low-risk (light shaded) genotypes among the markers studied. The summary of the distribution illustrates the hypertensives (left bars) and normotensives (right bars) for each genotype combination. Asterisk (*) indicates the significant difference between cases and control subjects.

MDR interaction information analysis of all four polymorphisms studied gene, represented in the form of a dendrogram. The MDR analysis shows synergistic effect of $A C E$ and AGT polymorphisms in the EHT patients. To improve the quality of analysis and identify the disease risk, we have carried out combination analysis and haplotype frequencies on the basis of the polymorphism pairs selected by MDR analysis. Similar analysis between gene-environmental interactions showed moderate synergistic effect of the marker $A G T \mathrm{M} 235 \mathrm{~T}$ and ACE I/D with the sex in the development of EHT (Figure 1). Table 5 summarizes the results of the MDR analysis evaluated for all possible combinations of the polymorphisms studied for the risk of developing hypertension. It shows the best model with a combination of polymorphisms in order along with its prediction error and coefficient of variation (CV) consistency. Result reveals the interaction of $A G T$ M235T-ACE I/D polymorphisms as the overall best models with least prediction error of 0.39 and CV consistency of 10/10. High-risk (dark grey) and low-risk (light grey) genotypic combinations were determined based on the threshold value, which was 1.0 (211/211) for the present data. It was observed that TT genotype of AGT M235T polymorphism when present in combination with DD genotype of $A C E \mathrm{I} / \mathrm{D}$ polymorphism conferred a 2.5 times higher risk (56/22) for developing EHT (Figure 2). 
TABLE 3: Distribution of genotype frequencies of RAS gene polymorphisms in patients and control subjects.

\begin{tabular}{|c|c|c|c|c|c|c|}
\hline SNPs & Genotype & Case $\%(N=211)$ & Control \% $(N=211)$ & OR & $95 \% \mathrm{CI}$ & $P$ value \\
\hline \multirow{3}{*}{$A G T \mathrm{M} 235 \mathrm{~T}$} & MM & 6.16 & 14.22 & Ref & & \\
\hline & MT & 38.39 & 36.97 & 2.40 & $1.11-5.37$ & 0.016 \\
\hline & $\mathrm{TT}$ & 55.45 & 48.82 & 2.62 & $1.24-5.76$ & $0.006^{*}$ \\
\hline \multirow{3}{*}{ Male } & MM & 8.26 & 12.31 & Ref & & \\
\hline & MT & 39.45 & 36.92 & 1.59 & $0.59-4.52$ & 0.320 \\
\hline & TT & 52.29 & 50.77 & 1.54 & $0.58-4.25$ & 0.340 \\
\hline \multirow{3}{*}{ Female } & MM & 3.92 & 17.28 & Ref & & \\
\hline & MT & 37.25 & 37.04 & 4.43 & $1.21-20.09$ & 0.011 \\
\hline & TT & 58.82 & 45.68 & 5.68 & $1.60-25.10$ & $0.002^{*}$ \\
\hline \multirow{3}{*}{$A C E \mathrm{I} / \mathrm{D}$} & II & 18.96 & 24.17 & Ref & & \\
\hline & ID & 41.71 & 44.08 & 1.21 & $0.71-2.07$ & 0.467 \\
\hline & DD & 39.34 & 31.75 & 1.58 & $0.90-2.76$ & 0.087 \\
\hline \multirow{3}{*}{ Male } & II & 17.43 & 23.08 & Ref & & \\
\hline & ID & 36.70 & 51.54 & 0.94 & $0.45-2.02$ & 0.870 \\
\hline & $\mathrm{DD}$ & 45.87 & 25.38 & 2.39 & $1.09-5.27$ & 0.020 \\
\hline \multirow{3}{*}{ Female } & II & 20.59 & 25.93 & Ref & & \\
\hline & ID & 47.06 & 32.10 & 1.85 & $0.80-4.28$ & 0.117 \\
\hline & $\mathrm{DD}$ & 32.35 & 41.98 & 0.97 & $0.42-2.25$ & 0.940 \\
\hline \multirow{3}{*}{ ACE G2350A } & GG & 71.09 & 72.51 & Ref & & \\
\hline & GA & 23.22 & 22.27 & 1.06 & $0.65-1.73$ & 0.793 \\
\hline & AA & 5.69 & 5.21 & 1.11 & $0.43-2.88$ & 0.805 \\
\hline \multirow{3}{*}{ Male } & GG & 71.56 & 77.69 & Ref & & \\
\hline & GA & 22.02 & 17.69 & 1.51 & $0.42-5.66$ & 0.472 \\
\hline & $\mathrm{AA}$ & 6.42 & 4.62 & 1.35 & $0.67-2.71$ & 0.359 \\
\hline \multirow{3}{*}{ Female } & GG & 70.59 & 64.20 & Ref & & \\
\hline & GA & 24.51 & 29.63 & 0.75 & $0.37-1.54$ & 0.400 \\
\hline & AA & 4.90 & 6.17 & 0.72 & $0.16-3.32$ & 0.620 \\
\hline \multirow{3}{*}{ AGTR1 A1166C } & $\mathrm{AA}$ & 41.71 & 40.28 & Ref & & \\
\hline & $\mathrm{AC}$ & 39.81 & 39.34 & 0.98 & $0.62-1.53$ & 0.917 \\
\hline & $\mathrm{CC}$ & 18.48 & 20.38 & 0.88 & $0.50-1.53$ & 0.622 \\
\hline \multirow{3}{*}{ Male } & AA & 37.61 & 40.77 & Ref & & \\
\hline & $\mathrm{AC}$ & 44.04 & 40.00 & 1.03 & $0.47-2.24$ & 0.540 \\
\hline & CC & 18.35 & 19.23 & 1.19 & $0.65-2.19$ & 0.930 \\
\hline \multirow{3}{*}{ Female } & AA & 46.08 & 39.51 & Ref & & \\
\hline & $\mathrm{AC}$ & 35.29 & 38.27 & 0.79 & $0.39-1.61$ & 0.484 \\
\hline & $\mathrm{CC}$ & 18.63 & 22.22 & 0.72 & $0.30-1.70$ & 0.409 \\
\hline
\end{tabular}

$N$ : sample size; OR: odds ratio; CI: confidence interval; Ref: reference; ${ }^{*} P<0.05$ : statically significant.

\section{Genetic Power Test}

We estimated the genetic power using the M235T polymorphism as an example; an $80 \%$ power should have to detect linkage between hypertension and $\mathrm{T}$ allele at type I error of 0.05 when the sample includes 211 cases and 211 controls. We also performed post hoc exploratory analyses to examine the relationships of the polymorphisms with cases and control subjects. Genetic power estimation showed that 211 cases and 211 controls had $>80 \%$ power to detect linkage between $\mathrm{M} 235 \mathrm{~T}$ variant and hypertension in south Indian population.

\section{Discussion}

The renin-angiotensin system is a major endocrine/paracrine system that regulates blood pressure (BP) in our body
[49], genes encoding components of this system have been strong candidates for the investigation of the genetic basis of essential hypertension and major targets for antihypertensive drugs [50]. However, previous studies in south India mainly focus on limited gene of RAS [47, 48, 51]; thus we carried out a case-control study to systemically investigate the association between polymorphisms in RAS genes and essential hypertension. The present study identifies gender specific genetic variants in RAS genes that may play crucial roles in BP regulation and susceptibility for hypertension. A significantly higher frequency of the AGT 235TT was observed in female patients when compared to the female controls. ACE DD was more prevalent in male patients when compared with male controls. So, AGT M235T was associated with EHT in females and $A C E \mathrm{I} / \mathrm{D}$ was associated with males in our study population. Association of $\mathrm{T}$ variant with the essential 
TABLE 4: Distribution of RAS gene polymorphisms (dominant and recessive model) in patient and control subjects.

\begin{tabular}{|c|c|c|c|c|c|c|c|}
\hline SNPs & Model & TEST & Case $(N)$ & Control $(N)$ & OR & $95 \% \mathrm{CI}$ & $P$ value \\
\hline \multirow{2}{*}{$A G T \mathrm{M} 235 \mathrm{~T}$} & $\mathrm{MM}+\mathrm{MT}$ versus TT & $\mathrm{DOM}$ & $94 / 117$ & $108 / 103$ & 0.766 & $0.513-1.144$ & 0.173 \\
\hline & $\mathrm{MM}$ versus $\mathrm{MT}+\mathrm{TT}$ & REC & $13 / 198$ & $30 / 181$ & 0.396 & $0.184-0.813$ & $0.006^{*}$ \\
\hline \multirow{2}{*}{ Male } & $\mathrm{MM}+\mathrm{MT}$ versus TT & $\mathrm{DOM}$ & $52 / 57$ & $64 / 66$ & 0.941 & $0.547-1.616$ & 0.814 \\
\hline & $\mathrm{MM}$ versus $\mathrm{MT}+\mathrm{TT}$ & REC & $9 / 100$ & $16 / 114$ & 0.641 & $0.239-1.624$ & 0.308 \\
\hline \multirow{2}{*}{ Female } & $\mathrm{MM}+\mathrm{MT}$ versus TT & $\mathrm{DOM}$ & $42 / 60$ & $44 / 37$ & 0.589 & $0.313-1.106$ & 0.077 \\
\hline & $\mathrm{MM}$ versus $\mathrm{MT}+\mathrm{TT}$ & REC & $04 / 98$ & $14 / 67$ & 0.062 & $0.015-0.185$ & 0.000 \\
\hline \multirow{2}{*}{$A C E \mathrm{I} / \mathrm{D}$} & $\mathrm{II}+\mathrm{ID}$ versus DD & $\mathrm{DOM}$ & $128 / 83$ & $144 / 67$ & 0.718 & $0.471-1.092$ & 0.104 \\
\hline & II versus ID + DD & REC & $40 / 171$ & $51 / 160$ & 0.734 & $0.447-1.201$ & 0.193 \\
\hline \multirow{2}{*}{ Male } & $\mathrm{II}+\mathrm{ID}$ versus $\mathrm{DD}$ & $\mathrm{DOM}$ & $59 / 50$ & $97 / 33$ & 0.401 & $0.224-0.718$ & $0.0009^{*}$ \\
\hline & II versus ID + DD & REC & $19 / 90$ & $30 / 100$ & 0.704 & $0.349-1.397$ & 0.282 \\
\hline \multirow{2}{*}{ Female } & $\mathrm{II}+\mathrm{ID}$ versus DD & $\mathrm{DOM}$ & $69 / 33$ & $47 / 34$ & 1.513 & $0.789-2.898$ & 0.180 \\
\hline & II versus ID + DD & REC & $21 / 81$ & $21 / 60$ & 0.741 & $0.350-1.569$ & 0.394 \\
\hline \multirow{2}{*}{$A C E \mathrm{G} 2350 \mathrm{~A}$} & $\mathrm{AA}+\mathrm{AG}$ versus $\mathrm{GG}$ & $\mathrm{DOM}$ & $61 / 150$ & $58 / 153$ & 1.073 & $0.686-1.677$ & 0.746 \\
\hline & AA versus $A G+G G$ & REC & $12 / 199$ & $11 / 200$ & 1.096 & $0.432-2.813$ & 0.830 \\
\hline \multirow{2}{*}{ Male } & $\mathrm{AA}+\mathrm{AG}$ versus GG & $\mathrm{DOM}$ & $31 / 78$ & 29/101 & 1.384 & $0.738-2.596$ & 0.276 \\
\hline & AA versus AG + GG & REC & $7 / 102$ & $6 / 124$ & 1.418 & $0.394-0.273$ & 0.540 \\
\hline \multirow{2}{*}{ Female } & $\mathrm{AA}+\mathrm{AG}$ versus $\mathrm{GG}$ & $\mathrm{DOM}$ & $30 / 72$ & $29 / 52$ & 0.747 & $0.383-1.462$ & 0.358 \\
\hline & AA versus AG + GG & REC & $05 / 97$ & $05 / 76$ & 0.784 & $0.174-0.542$ & 0.707 \\
\hline \multirow{2}{*}{ A1166C } & $\mathrm{CC}+\mathrm{CT}$ versus TT & $\mathrm{DOM}$ & $123 / 88$ & $126 / 85$ & 0.943 & $0.628-1.416$ & 0.767 \\
\hline & $\mathrm{CC}$ versus $\mathrm{CT}+\mathrm{TT}$ & REC & $39 / 172$ & $43 / 168$ & 0.886 & $0.530-1.477$ & 0.623 \\
\hline \multirow{2}{*}{ Male } & $\mathrm{CC}+\mathrm{CA}$ versus $\mathrm{AA}$ & $\mathrm{DOM}$ & $68 / 41$ & $77 / 53$ & 1.142 & $0.656-1.992$ & 0.619 \\
\hline & $\mathrm{CC}$ versus $\mathrm{CA}+\mathrm{AA}$ & REC & $20 / 89$ & $25 / 105$ & 0.944 & $0.464-1.903$ & 0.862 \\
\hline \multirow{2}{*}{ Female } & $\mathrm{CC}+\mathrm{CA}$ versus $\mathrm{AA}$ & $\mathrm{DOM}$ & $55 / 47$ & $49 / 32$ & 0.764 & $0.405-1.439$ & 0.373 \\
\hline & $\mathrm{CC}$ versus $\mathrm{CA}+\mathrm{AA}$ & REC & $19 / 83$ & $18 / 63$ & 0.801 & $0.365-1.767$ & 0.548 \\
\hline
\end{tabular}

DOM: dominant model; REC: recessive model; $N$ : sample size; OR: odds ratio; CI: confidence interval; ${ }^{*} P<0.05$ : statically significant.

TABLE 5: Summary of MDR analysis. MDR analysis reveals that combination of ACE I/D and AGT M235T could be a high risk for the prevalence of the EHT.

\begin{tabular}{lcccc}
\hline Model & Training bal. acc. (\%) & Testing bal. acc. (\%) & Cross-validation consistency & Prediction error \\
\hline Sex & 0.550 & 0.528 & $08 / 10$ & 0.450 \\
I/D, M235T & $\mathbf{0 . 6 1 3}$ & $\mathbf{0 . 5 9 5}$ & $\mathbf{1 0 / 1 0}$ & $\mathbf{0 . 3 8 7}$ \\
I/D, M235T, and A1166C & 0.655 & 0.569 & $6 / 10$ & 0.345 \\
I/D, M235T, A1166C, and sex & 0.710 & 0.602 & $7 / 10$ & 0.290 \\
\hline
\end{tabular}

hypertension in our study has shown agreement with some studies.

Jeunemaitre et al., 1992 [4], were the first to report the linkage of the molecular variants M235T with hypertension in the Caucasians. Subsequent studies among the UK/Chinese/Malaysian/south Indian supported the former finding $[15,40,47,48,52]$ while a study of Germany/North India is inconsistent with the previous report $[47,53]$. The association studies in the Africans/African-Americans mostly found a negative association $[54,55]$, but the high frequency of $\mathrm{T}$ allele was observed in this population and it is associated with increase in plasma and mRNA $A G T$ concentration $[11,55,56]$.

The frequency of the $235 \mathrm{~T}$ variant (major allele in our study) was 0.746 for this study among cases and this frequency was similar to study already reported in Chinese
(0.73) and Hong Kong Chinese (0.82) population [16, 57]. The frequency of 235T variant in the 1000 genome project was found to be 0.87 in Africans, 0.64 in Americans, and 0.84 in Asians but the frequency was deviated in Europeans with the frequency of 0.41 [58]. Several studies in south India has reported that the $235 \mathrm{~T}$ frequencies are in the range of $0.56-0.81$ in the patients $[13,59-61]$. But in north India the frequency was reported to be 0.31 in the cases [44]. Prasad and colleague have performed a comparative study of north and south India in control subjects and 235T variant frequency was found to be 0.33 and 0.52 , respectively [62]. These overall results show that $235 \mathrm{~T}$ variant is predominantly present in south India compared to north India. Our study showed a higher OR 2.62 (95\% CI, 1.24-5.76; $P=0.006$ ) compared to a recent meta-analysis [15] in Han Chinese population which reports high association between $A G T$ 
M235T polymorphism and hypertension $(\mathrm{OR}=1.54 ; 95 \% \mathrm{CI}$, $1.16-2.03 ; P=0.002)$. On the contrary, another meta-analysis of 126 studies by Sethi et al. (2003) has reported that odds ratio for hypertension was 1.19 (1.10 to 1.30) in TT individuals in white subjects and 1.60 (1.19 to 2.15) in Asian subjects and it was not associated with SBP or DBP [63]. Instead, M235T genotype was associated with a stepwise increase in angiotensinogen levels in white subjects and a corresponding increase in risk of hypertension in both White and Asian subjects [63]. In another meta-analysis, the frequencies of the AGT T allele were $80 \%$ in cases and $72 \%$ in controls. The pooled OR (with $95 \% \mathrm{CI}$ ) of TT versusMT + MM was 1.76 $(1.44-2.16)(P<0.00001)$ with $\mathrm{T}$ versus $\mathrm{M}$ of $1.54(1.31-1.81)$. The pooled OR of MM versus MT + TT was 0.67 (0.45-1.00) $(P=0.05)[16]$.

In this study, the significantly higher prevalence of $235 \mathrm{~T}$ allele in female patients is in agreement with the previous report that the $\mathrm{T}$ allele was significantly more prevalent among female ETH than in control subjects [4]. In contrast, Freire et al. (1998) [64] found that the AGT M235T homozygous mutation genotype was significantly higher in males compared to females. Earlier studies have found that plasma $A G T$ levels in postmenopausal women are slightly higher [65] than in men [66]. Plasma angiotensinogen levels are more increased in M235T variant than the $235 \mathrm{M}$ variant with administration of ethinyl estradiol (EE), a synthetic estrogen. The AGT G (-6) variant is less transcriptionally active with lower levels of AGT mRNA [16,67] and a significant linkage disequilibrium between M235T and G6A was also reported. These findings reveals that G-6A polymorphism, which is linked to nonfunctioning M235T, increased the plasma $A G T$ level via regulation of $A G T$ gene transcription and was involved in the pathogenesis of the predisposition to hypertension. Thus, sex hormones such as estrogen might bind to the core promoter region and enhance the transcription of $A G T$ gene. However, it is also can be hypothesized that estrogen may bind to the $-6 \mathrm{~A}$ variant more effectively and $A G T$ gene expression could be more in this variant. Hence, the angiotensinogen promoter is directly controlled by estrogen $[68,69]$.

The I/D allelic variant (intronic deletion of a $287 \mathrm{bp} \mathrm{Alu}$ sequence repetitive element, $\mathrm{D}$ allele) is one of the most intensively investigated genetic polymorphism in the field of hypertension and cardiovascular disease research [70, 71]. In the present study, dominant model of $A C E$ gene in male (II + ID versus DD) is associated with EHT in south Indian and it was also observed that I allele has a protective role. Overrepresentation of $\mathrm{D}$ allele in male cases represents strong association in pathogenesis of hypertension in male. This is in accordance with the previous report by many studies [7274]. Our study showed a lower OR 0.401 (95\% CI $0.224-$ $0.718 ; P<0.01)$ compared to a recent meta-analysis [22] in whole Chinese population which reports high association with $A C E \mathrm{DD}$ polymorphism with hypertension $(\mathrm{OR}=1.27$; 95\% CI 1.17-1.46; $P<0.01$ ). The D allele of $A C E$ was initially suggested to be associated with increased levels of serum $A C E$ activity as compared with I variant $[75,76]$. In contrast to this, Zee et al. (1992) has reported that "I" allele was associated with high blood pressure in an Australian population with strong evidence of familial hypertension [77]. In recent meta-analysis, the distribution of the $\mathrm{D}$ allele frequency was 0.45 for the EH group and 0.40 for the control group. The summary OR for the distribution frequency of D allele was 1.27 (5\% CI 1.17-1.37). The heterogeneity among the 67 studies was also significant $(P<0.00001$, $I(2)=71.4 \%)$. There was a significant association between distribution frequency of the D allele and EH risk in Han, Kazakh, Tibetan, Zhuang, and unclassified nationalities $(P<$ $0.05)$. Contradictory result was observed in the national minorities, such as Mongolian, Uighur, Yi, Dongxiang, Yugu, Korean and Gamel, and the $D$ allele; and EH risk was not significant $(P>0.05)$ [22].

The mechanism of the sex specific association with hypertension remains unclear. One notion is that estrogen protects against hypertension. Even though estrogen upregulates the $A G T$ gene expression but it again acts as negative feedback mechanism in controlling renin secretion and then the ACE secretion in RAS [78]. Sex differences exist in the regulation of arterial pressure and renal function by RAS. This may in part stem from a differential balance in the pressor and depressor arms of the RAS (Hilliard et al., 2013). In males, the ACE/AngII/AGTR1 pathways are enhanced, whereas, in females, the balance is shifted towards the ACE2/Ang(17)/MasR (Mas receptor) and angiotensin type 2 receptor $\left(\mathrm{AT}_{2} \mathrm{R}\right)$ pathways [79]. Studies reported that premenopausal women, as compared to age matched men, are protected from renal and cardiovascular disease, and this differential balance of the RAS between the sexes likely contributes [80, 81].

There were some limitations in this study. First, the age and sex match case control was not available in the sample studied. Our approach is based on a sample with a relatively homogeneous genetic background, and therefore the results are unlikely to be affected by unmeasured confounding factors of population stratification. This study did not measure central obesity and psychiatric comorbidities, the major risk factor for hypertension. There are no measurements of plasma angiotensinogen levels or other markers of RAS activation available to correlate directly with the genetic polymorphisms investigated in this study.

\section{Conclusion}

In summary, the genotype distributions of the AGT M235T polymorphism influenced the risk of essential hypertension in south Indian women and ACE DD is a risk in south Indian male population. MDR analysis reveals that if both TT and DD genotypes are present, prevalence of EHT is higher in the present study. The haplotype based MDR analysis suggests that we had adequate power to detect the functional relationship of the best factor model, increasing the risk of essential hypertension associated with combined genetic variations. This is the first report to evaluate the simultaneous association of ACE, AGTR1, and AGT gene polymorphisms in essential hypertension by haplotype based analyses and gender specific association in south India. Future studies are required to consider the joint effects of several candidate genes to dissect the genetic framework and gender specific association of essential hypertension. 


\section{Conflict of Interests}

The authors declare that there is no conflict of interests regarding the publication of this paper.

\section{Acknowledgments}

This work was supported by the University Grant Commission (UGC), Government of India, Grant no. 37-12/2009 (SR). Kh. Dhanachandra Singh gratefully acknowledges CSIR for providing the Senior Research Fellowship (SRF). The authors thank all the patients and control volunteers for their participation in this study. The suggestions from the anonymous reviewers of this paper are cordially appreciated.

\section{References}

[1] J. Baima, M. Nicolaou, F. Schwartz et al., "Evidence for linkage between essential hypertension and a putative locus on human chromosome 17," Hypertension, vol. 34, no. 1, pp. 4-7, 1999.

[2] R. P. Lifton, A. G. Gharavi, and D. S. Geller, "Molecular mechanisms of human hypertension," Cell, vol. 104, no. 4, pp. 545-556, 2001.

[3] T. Škarić-Jurić, "Path analysis of familial resemblance in blood pressure in Middle Dalmatia, Croatia," Collegium Antropologicum, vol. 27, no. 1, pp. 229-237, 2003.

[4] X. Jeunemaitre, F. Soubrier, Y. V. Kotelevtsev et al., "Molecular basis of human hypertension: role of angiotensinogen," Cell, vol. 71, no. 1, pp. 169-180, 1992.

[5] C. J. O’Donnell, K. Lindpaintner, M. G. Larson et al., "Evidence for association and genetic linkage of the angiotensinconverting enzyme locus with hypertension and blood pressure in men but not women in the Framingham heart study," Circulation, vol. 97, no. 18, pp. 1763-1772, 1998.

[6] J. P. Forman, N. D. Fisher, M. R. Pollak et al., "Renin-angiotensin system polymorphisms and risk of hypertension: influence of environmental factors," Journal of Clinical Hypertension, vol. 10, no. 6, pp. 459-466, 2008.

[7] A. Tsezou, G. Karayannis, E. Giannatou, V. Papanikolaou, and F. Triposkiadis, "Association of renin-angiotensin system and natriuretic peptide receptor A gene polymorphisms with hypertension in a Hellenic population," Journal of the ReninAngiotensin-Aldosterone System, vol. 9, no. 4, pp. 202-207, 2008.

[8] M. Fornage, S. T. Turner, C. F. Sing, and E. Boerwinkle, "Variation at the M235T locus of the angiotensinogen gene and essential hypertension: a population-based case-control study from Rochester, Minnesota," Human Genetics, vol. 96, no. 3, pp. 295-300, 1995.

[9] B. J. Morris, R. Y. L. Zee, and A. P. Schrader, "Different frequencies of angiotensin-converting enzyme genotypes in older hypertensive individuals," Journal of Clinical Investigation, vol. 94, no. 3, pp. 1085-1089, 1994.

[10] L. A. Hindorff, S. R. Heckbert, R. Tracy et al., "Angiotensin II type 1 receptor polymorphisms in the cardiovascular health study: relation to blood pressure, ethnicity, and cardiovascular events," The American Journal of Hypertension, vol. 15, no. 12, pp. 1050-1056, 2002.

[11] L. J. Bloem, T. M. Foroud, W. T. Ambrosius, M. P. Hanna, D. A. Tewksbury, and J. H. Pratt, "Association of the angiotensinogen gene to serum angiotensinogen in blacks and whites," Hypertension, vol. 29, no. 5, pp. 1078-1082, 1997.
[12] X. Wu, A. Luke, M. Rieder et al., "An association study of angiotensinogen polymorphisms with serum level and hypertension in an African-American population," Journal of Hypertension, vol. 21, no. 10, pp. 1847-1852, 2003.

[13] V. U. Mohana, N. Swapna, R. S. Surender, S. Vishnupriya, and T. Padma, "Gender-related association of AGT gene variants (M235T and T174M) with essential hypertension: a case-control study," Clinical and Experimental Hypertension, vol. 34, no. 1, pp. 38-44, 2012.

[14] A. Rudnichi, M. E. Safar, M. Lajemi, and A. Benetos, "Gene polymorphisms of the renin-angiotensin system and agerelated changes in systolic and diastolic blood pressure in subjects with hypertension," The American Journal of Hypertension, vol. 17, no. 4, pp. 321-327, 2004.

[15] L.-D. Ji, L.-N. Zhang, P. Shen et al., "Association of angiotensinogen gene M235T and angiotensin-converting enzyme gene I/D polymorphisms with essential hypertension in Han Chinese population: a meta-analysis," Journal of Hypertension, vol. 28, no. 3, pp. 419-428, 2010.

[16] J.-L. Cheng, A.-L. Wang, and J. Wan, "Association between the M235T polymorphism of the AGT gene and cytokines in patients with hypertension," Experimental and Therapeutic Medicine, vol. 3, no. 3, pp. 509-512, 2012.

[17] K. E. Bernstein, H. D. Xiao, J. W. Adams et al., "Establishing the role of angiotensin-converting enzyme in renal function and blood pressure control through the analysis of genetically modified mice," Journal of the American Society of Nephrology, vol. 16, no. 3, pp. 583-591, 2005.

[18] J.-G. Wang and J. A. Staessen, "Genetic polymorphisms in the renin-angiotensin system: relevance for susceptibility to cardiovascular disease," European Journal of Pharmacology, vol. 410, no. 2-3, pp. 289-302, 2000.

[19] T. Sakuma, R. D. C. Hirata, and M. H. Hirata, "Five polymorphisms in gene candidates for cardiovascular disease in AfroBrazilian individuals," Journal of Clinical Laboratory Analysis, vol. 18, no. 6, pp. 309-316, 2004.

[20] J. Higaki, S. Baba, T. Katsuya et al., "Deletion allele of angiotensin-converting enzyme gene increases risk of essential hypertension in Japanese men: the Suita study," Circulation, vol. 101, no. 17, pp. 2060-2065, 2000.

[21] M. M. Zaman, N. Yoshiike, C. Date et al., "Angiotensin converting enzyme genetic polymorphism is not associated with hypertension in a cross-sectional sample of a Japanese population: the shibata study," Journal of Hypertension, vol. 19, no. 1, pp. 47-53, 2001.

[22] Y. Li, "Angiotensin-converting enzyme gene insertion/deletion polymorphism and essential hypertension in the Chinese population: a meta-analysis including 21,058 participants," Internal Medicine Journal, vol. 42, no. 4, pp. 439-444, 2012.

[23] H. Qu, Y. Lu, and S. Lin, "Meta-analysis on the association of ACE/ID polymorphism and essential hypertension in Chinese population," Zhonghua yu fang yi xue za zhi, vol. 35, no. 6, pp. 408-411, 2001.

[24] W. Niu, Y. Qi, P. Gao, and D. Zhu, "Association between angiotensin converting enzyme G2350A polymorphism and hypertension risk: a meta-analysis," Journal of the ReninAngiotensin-Aldosterone System, vol. 12, no. 1, pp. 8-14, 2011.

[25] S. Kim and H. Iwao, "Molecular and cellular mechanisms of angiotensin II-mediated cardiovascular and renal diseases," Pharmacological Reviews, vol. 52, no. 1, pp. 11-34, 2000. 
[26] J. R. Ingelfinger, "Angiotensin-converting enzyme 2: implications for blood pressure and kidney disease," Current Opinion in Nephrology and Hypertension, vol. 18, no. 1, pp. 79-84, 2009.

[27] A. Bonnardeaux, E. Davies, X. Jeunemaitre et al., "Angiotensin II type 1 receptor gene polymorphisms in human essential hypertension," Hypertension, vol. 24, no. 1, pp. 63-69, 1994.

[28] D. S. Shahin, Y. M. Irshaid, and A. A. Saleh, “The A(1166)C26 polymorphism of the AGTR1 gene is associated with an early onset of hypertension and high waist circumference in Jordanian males attending the Jordan University Hospital," Clinical and Experimental Hypertension. In press.

[29] J.-L. Wang, L. Xu, P.-P. Hao, F. Xu, Y.-G. Chen, and Y. Zhang, "Angiotensin II type 1 receptor gene A1166C polymorphism and essential hypertension in Chinese: a meta-analysis," Journal of the Renin-Angiotensin-Aldosterone System, vol. 11, no. 2, pp. 127$135,2010$.

[30] K. Sugimoto, T. Katsuya, T. Ohkubo et al., "Association between angiotensin II type 1 receptor gene polymorphism and essential hypertension: the Ohasama study," Hypertension Research, vol. 27, no. 8, pp. 551-556, 2004.

[31] Y. Liu, C. Zhuoma, G. Shan et al., "A1166C polymorphism of the angiotensin II type 1 receptor gene and essential hypertension in Han, Tibetan and Yi populations," Hypertension Research, vol. 25 , no. 4, pp. 515-521, 2002.

[32] M. L. S. Cuddy, "Treatment of hypertension: guidelines from JNC 7 (the seventh report of the joint national committee on prevention, detection, evaluation, and treatment of high blood pressure 1)," The Journal of Practical Nursing, vol. 55, no. 4, pp. 17-23, 2005.

[33] S. A. Miller, D. D. Dykes, and H. F. Polesky, "A simple salting out procedure for extracting DNA from human nucleated cells," Nucleic Acids Research, vol. 16, no. 3, Article ID 1215, 1988.

[34] S. Purcell, B. Neale, K. Todd-Brown et al., "PLINK: a tool set for whole-genome association and population-based linkage analyses," The American Journal of Human Genetics, vol. 81, no. 3, pp. 559-575, 2007.

[35] W. D. Dupont and W. D. Plummer Jr., "Power and sample size calculations for studies involving linear regression," Controlled Clinical Trials, vol. 19, no. 6, pp. 589-601, 1998.

[36] M. D. Ritchie, L. W. Hahn, N. Roodi et al., "Multifactordimensionality reduction reveals high-order interactions among estrogen-metabolism genes in sporadic breast cancer," The American Journal of Human Genetics, vol. 69, no. 1, pp. 138-147, 2001.

[37] S. Yeoun Lee, Y. Chung, R. C. Elston, Y. Kim, and T. Park, "Log-linear model-based multifactor dimensionality reduction method to detect gene-gene interactions," Bioinformatics, vol. 23, no. 19, pp. 2589-2595, 2007.

[38] J. H. Moore, J. C. Gilbert, C.-T. Tsai et al., "A flexible computational framework for detecting, characterizing, and interpreting statistical patterns of epistasis in genetic studies of human disease susceptibility," Journal of Theoretical Biology, vol. 241, no. 2, pp. 252-261, 2006.

[39] N. E. Morton and A. Collins, "Tests and estimates of allelic association in complex inheritance," Proceedings of the National Academy of Sciences of the United States of America, vol. 95, no. 19, pp. 11389-11393, 1998.

[40] V. Ramachandran, P. Ismail, J. Stanslas, and N. Shamsudin, "Analysis of renin-angiotensin aldosterone system gene polymorphisms in malaysian essential hypertensive and type 2 diabetic subjects," Cardiovascular Diabetology, vol. 8, article 11, 2009.
[41] N. Devi, V. Lakshmi, K. Padhy et al., "Association of ACE, AGT and AGTR1 gene polymorphisms with severity of coronary artery disease," Journal of Dental and Medical Sciences, vol. 2, pp. 11-18, 2012.

[42] T. F. Ashavaid, K. K. Shalia, K. G. Nair et al., "ACE and AGTR1 gene polymorphisms and hypertension in Indian population," Journal of Clinical Laboratory Analysis, vol. 14, no. 5, pp. 230237, 2000.

[43] A. K. Islam and A. A. Majumder, "Hypertension in Bangladesh: a review," Indian Heart Journal, vol. 64, no. 3, pp. 319-323, 2012.

[44] Badaruddoza, A. J. S. Bhanwer, R. Sawhney, N. K. Randhawa, K. Matharoo, and B. Barna, "A study of angiotensin converting enzyme (ACE) gene polymorphism in essential hypertension among a business community in Punjab," International Journal of Human Genetics, vol. 9, no. 3-4, pp. 231-234, 2009.

[45] M. Das, S. Pal, and A. Ghosh, "Angiotensin converting enzyme gene polymorphism (Insertion/Deletion) and hypertension in adult Asian Indians: a population-based study from Calcutta, India," Human Biology, vol. 80, no. 3, pp. 303-312, 2008.

[46] K. Srivastava, S. Chandra, J. Bhatia et al., "Association of angiotensinogen (M235T) gene polymorphism with blood pressure lowering response to angiotensin converting enzyme inhibitor (Enalapril)," Journal of Pharmacy and Pharmaceutical Sciences, vol. 15, no. 3, pp. 399-406, 2012.

[47] B. Charita, G. Padma, P. Sushma et al., "Estimation of risk and interaction of single nucleotide polymorphisms at angiotensinogen locus causing susceptibility to essential hypertension: a case control study," Journal of the Renin-AngiotensinAldosterone System, vol. 13, no. 4, pp. 461-471, 2012.

[48] M. G. Chand, J. Srinath, R. S. Rao, B. V. K. S. Lakkakula, S. Kumar, and V. R. Rao, "Association between the M268T polymorphism in the angiotensinogen gene and essential hypertension in a South Indian population," Biochemical Genetics, vol. 49, no. 7-8, pp. 474-482, 2011.

[49] J.-B. Marteau, M. Zaiou, G. Siest, and S. Visvikis-Siest, "Genetic determinants of blood pressure regulation," Journal of Hypertension, vol. 23, no. 12, pp. 2127-2143, 2005.

[50] M. R. Weir and V. J. Dzau, "The renin-angiotensin-aldosterone system: a specific target for hypertension management," The American Journal of Hypertension, vol. 12, no. 12, pp. 205S-213S, 1999.

[51] M. Karthikeyan, R. Rose, V. Shridevi et al., "Core promoter variants (A-20C, T-18C and G-6A) of the angiotensinogen $(A G T)$ gene are not significantly associated with hypertension in patients of Tamilnadu, India," International Journal of Human Genetics, vol. 9, no. 1, pp. 13-19, 2009.

[52] A. D. Hingorani, P. Sharma, H. Jia et al., "Blood pressure and the M235T polymorphism of the angiotensinogen gene," Hypertension, vol. 28, pp. 907-911, 1996.

[53] J. R. Ortlepp, H. P. Vosberg, S. Reith et al., "Genetic polymorphisms in the renin-angiotensin-aldosterone system associated with expression of left ventricular hypertrophy in hypertrophic cardiomyopathy: a study of five polymorphic genes in a family with a disease causing mutation in the myosin binding protein C gene," Heart, vol. 87, no. 3, pp. 270-275, 2002.

[54] M. Caulfield, P. Lavender, J. Newell-Price et al., "Linkage of the angiotensinogen gene locus to human essential hypertension in African Caribbeans," Journal of Clinical Investigation, vol. 96, no. 2, pp. 687-692, 1995.

[55] C. Rotimi, L. Morrison, R. Cooper et al., "Angiotensinogen gene in human hypertension: lack of an association of the 235T allele 
among African Americans," Hypertension, vol. 24, no. 5, pp. 591594, 1994.

[56] D. Davis, N. Liyou, D. Lockwood, and A. Johnson, "Angiotensinogen genotype, plasma protein and mRNA concentration in isolated systolic hypertension," Clinical Genetics, vol. 61, no. 5, pp. 363-368, 2002.

[57] Y.-J. Fang, H.-B. Deng, G. N. Thomas et al., "Linkage of angiotensinogen gene polymorphisms with hypertension in a sibling study of Hong Kong Chinese," Journal of Hypertension, vol. 28, no. 6, pp. 1203-1209, 2010.

[58] 1000 Genomes Project Consortium, G. R. Abecasis, A. Auton et al., "An integrated map of genetic variation from 1,092 human genomes," Nature, vol. 491, no. 7422, pp. 56-65, 2012.

[59] M. Karthikeyan, V. Shridevi, R. Rose et al., "Angiotensin gene polymorphisms (T174M and M235T) are significantly associated with the hypertensive patients of Tamil Nadu, South India," International Journal of Human Genetics, vol. 13, no. 4, pp. 201-207, 2013.

[60] P. Ramu, G. Umamaheswaran, D. G. Shewade et al., "Candidate gene polymorphisms of renin angiotensin system and essential hypertension in a South Indian Tamilian population," International Journal of Human Genetics, vol. 11, no. 1, pp. 31-40, 2011.

[61] P. P. Kumar Manohar Rao, A. Munshi, R. Mullapudi et al., “The M235T polymorphism of the angiotensinogen gene in South Indian patients of hypertrophic cardiomyopathy," Journal of the Renin-Angiotensin-Aldosterone System, vol. 12, no. 3, pp. 238242, 2011.

[62] P. Prasad and B. K. Thelma, "Normative genetic profiles of RAAS pathway gene polymorphisms in North Indian and South Indian populations," Human Biology, vol. 79, no. 2, pp. 241-254, 2007.

[63] A. A. Sethi, B. G. Nordestgaard, and A. Tybæeg-Hansen, "Angiotensinogen gene polymorphism, plasma angiotensinogen, and risk of hypertension and ischemic heart disease: a meta-analysis," Arteriosclerosis, Thrombosis, and Vascular Biology, vol. 23, no. 7, pp. 1269-1275, 2003.

[64] M. B. S. Freire, L. Ji, T. Onuma, T. Orban, J. H. Warram, and A. S. Krolewski, "Gender-specific association of M235T polymorphism in angiotensinogen gene and diabetic nephropathy in NIDDM," Hypertension, vol. 31, no. 4, pp. 896-899, 1998.

[65] A. H. Jan Danser, F. H. M. Derkx, M. A. D. H. Schalekamp, H.W. Hense, G. A. J. Riegger, and H. Schunkert, "Determinants of interindividual variation of renin and prorenin concentrations: evidence for a sexual dimorphism of (pro)renin levels in humans," Journal of Hypertension, vol. 16, no. 6, pp. 853-862, 1998.

[66] H. Schunkert, A. H. Jan Danser, H.-W. Hense, F. H. M. Derkx, S. Kürzinger, and G. A. J. Riegger, "Effects of estrogen replacement therapy on the renin-angiotensin system in postmenopausal women," Circulation, vol. 95, no. 1, pp. 39-45, 1997.

[67] C.-C. Hsu, M. S. Bray, W. H. L. Kao, J. S. Pankow, E. Boerwinkle, and J. Coresh, "Genetic variation of the renin-angiotensin system and chronic kidney disease progression in black individuals in the atherosclerosis risk in communities study," Journal of the American Society of Nephrology, vol. 17, no. 2, pp. 504-512, 2006.

[68] E. Clauser, I. Gaillard, L. Wei, and P. Corvol, "Regulation of angiotensinogen gene," The American Journal of Hypertension, vol. 2, no. 5, pp. 403-410, 1989.

[69] M. Feldmer, M. Kaling, S. Takahashi, J. J. Mullins, and D. Ganten, "Glucocorticoid- and estrogen-responsive elements in the $5^{\prime}$-flanking region of the rat angiotensinogen gene," Journal of Hypertension, vol. 9, no. 11, pp. 1005-1012, 1991.
[70] J. A. Staessen, J. G. Wang, G. Ginocchio et al., “The deletion/insertion polymorphism of the angiotensin converting enzyme gene and cardiovascular-renal risk," Journal of Hypertension, vol. 15, no. 12, pp. 1579-1592, 1997.

[71] H. Schunkert, "Polymorphism of the angiotensin-converting enzyme gene and cardiovascular disease," Journal of Molecular Medicine, vol. 75, no. 11-12, pp. 867-875, 1997.

[72] M. Morshed, H. Khan, and S. Akhteruzzaman, "Association between angiotensin I-converting enzyme gene polymorphism and hypertension in selected individuals of the Bangladeshi population," Journal of Biochemistry and Molecular Biology, vol. 35, no. 3, pp. 251-254, 2002.

[73] J.-H. Yoo, "Deletion polymorphism in the gene for angiotensinconverting enzyme is associated with essential hypertension in men born during the Pacific War," Mechanisms of Ageing and Development, vol. 126, no. 8, pp. 899-905, 2005.

[74] J. Higaki, S. Baba, T. Katsuya et al., "Deletion allele of angiotensin-converting enzyme gene increases risk of essential hypertension in Japanese men: the Suita study," Circulation, vol. 101, no. 17, pp. 2060-2065, 2000.

[75] K. Nakai, C. Itoh, Y. Miura et al., "Deletion polymorphism of the angiotensin I-converting enzyme gene is associated with serum $A C E$ concentration and increased risk for CAD in the Japanese," Circulation, vol. 90, no. 5, pp. 2199-2202, 1994.

[76] L. Tiret, B. Rigat, S. Visvikis et al., "Evidence, from combined segregation and linkage analysis, that a variant of the angiotensin I-converting enzyme (ACE) gene controls plasma ACE levels," The American Journal of Human Genetics, vol. 51, no. 1, pp. 197-205, 1992.

[77] R. Y. L. Zee, Y.-K. Lou, L. R. Griffiths, and B. J. Morris, "Association of a polymorphism of the angiotensin I-converting enzyme gene with essential hypertension," Biochemical and Biophysical Research Communications, vol. 184, no. 1, pp. 9-15, 1992.

[78] M. Azizi, M. Hallouin, X. Jeunemaitre, T. T. Guyene, and J. Ménard, "Influence of the M235T polymorphism of human angiotensinogen $(A G T)$ on plasma $A G T$ and renin concentrations after ethinylestradiol administration," Journal of Clinical Endocrinology and Metabolism, vol. 85, no. 11, pp. 4331-4337, 2000.

[79] L. M. Hilliard, A. K. Sampson, R. D. Brown et al., "The "his and hers" of the renin-angiotensin system," Current Hypertension Reports, vol. 15, no. 1, pp. 71-79, 2013.

[80] D. Grady, S. M. Rubin, D. B. Petitti et al., "Hormone therapy to prevent disease and prolong life in postmenopausal women," Annals of Internal Medicine, vol. 117, no. 12, pp. 1016-1037, 1992.

[81] A. Bobik, "Striatin-dependent membrane estrogen receptor signaling and vasoprotection by estrogens," Circulation, vol. 126, no. 16, pp. 1941-1943, 2012. 

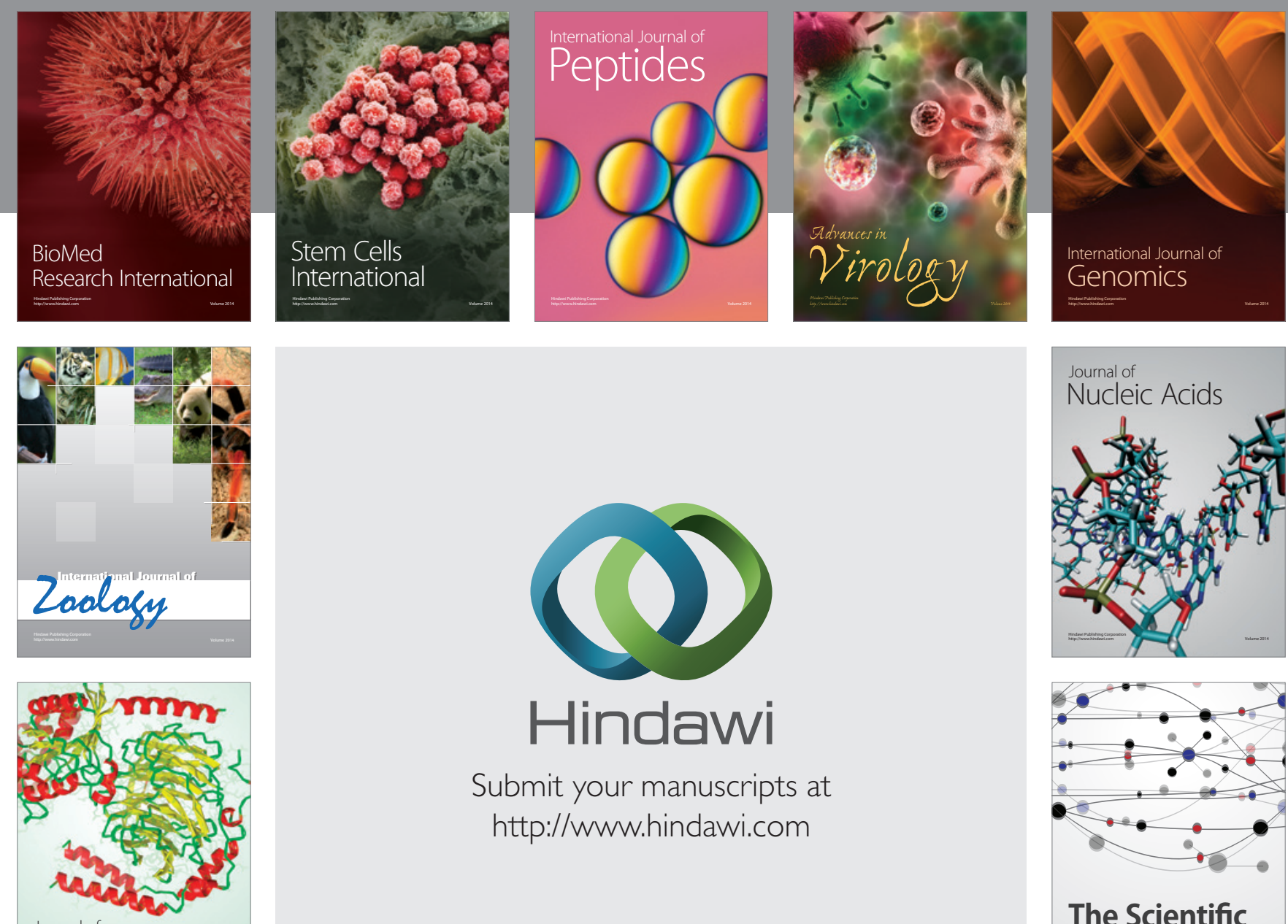

Submit your manuscripts at

http://www.hindawi.com

Journal of
Signal Transduction
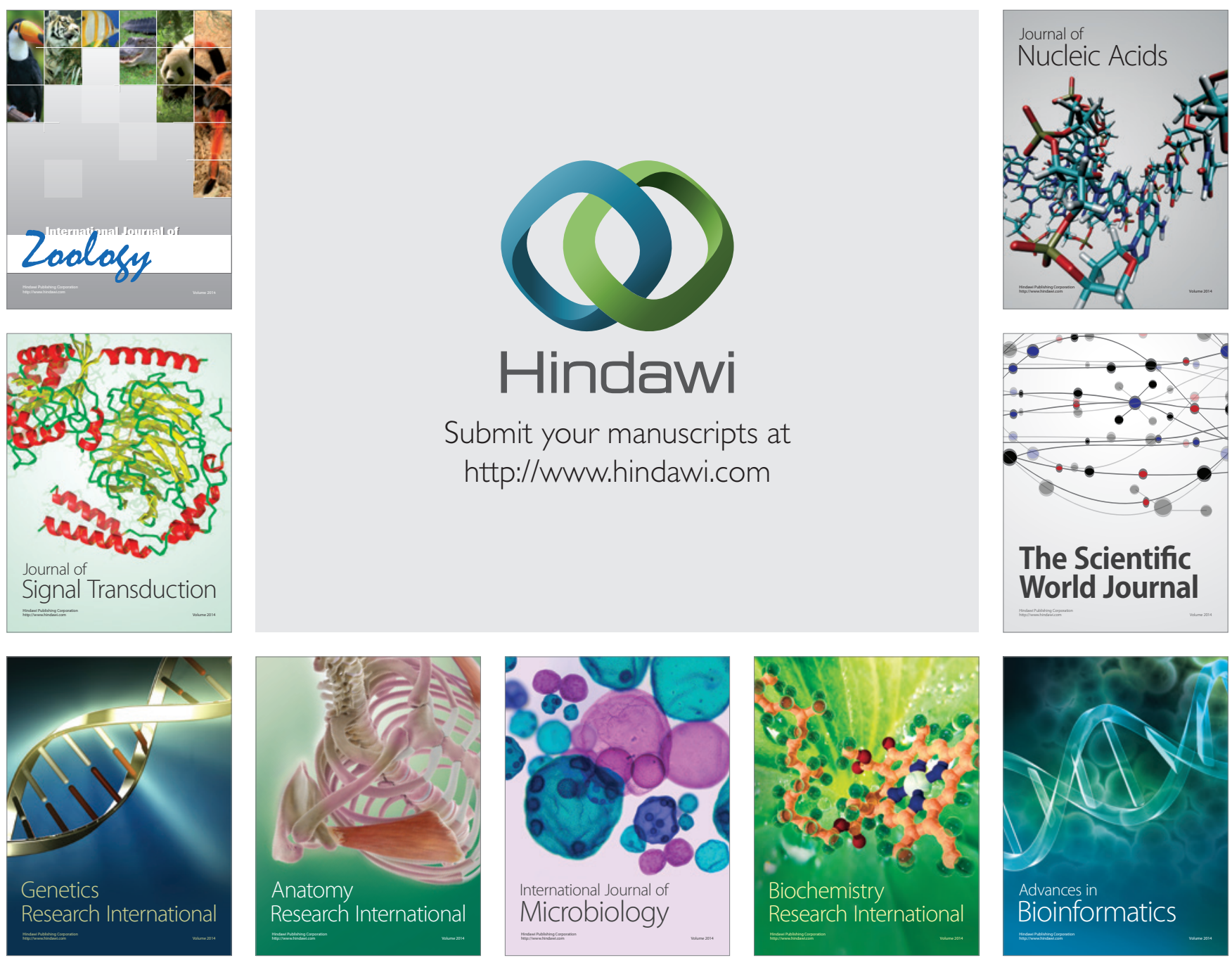

The Scientific World Journal
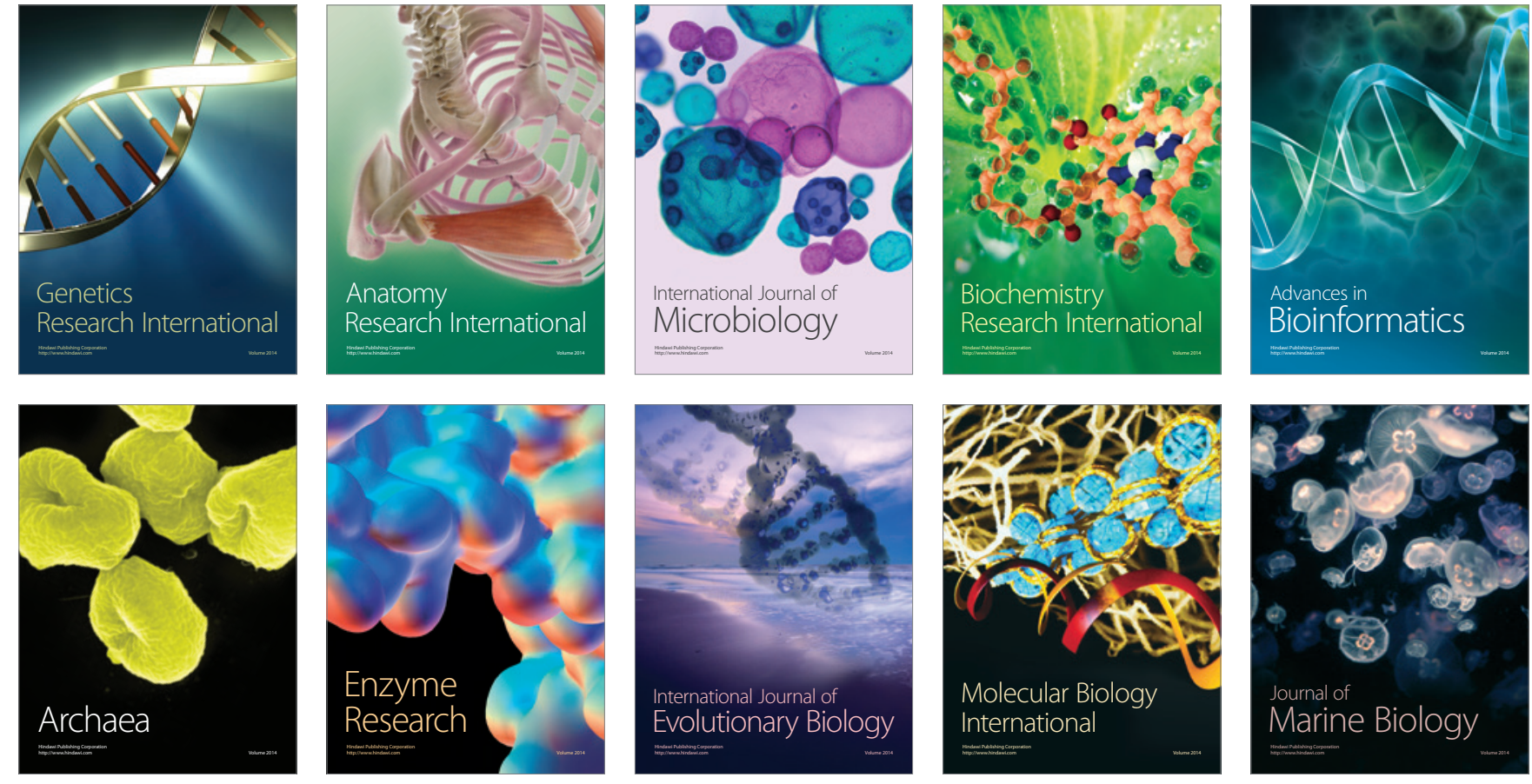